\title{
Sex-specific effects of gender identification on pain study recruitment
}

\section{Article}

\section{Accepted Version}

Creative Commons: Attribution-Noncommercial-No Derivative Works 4.0

Mattos Feijó, L., Tarman, G. Z., Fontaine, C., Harrison, R., Johnstone, T. and Salomons, T. V. (2018) Sex-specific effects of gender identification on pain study recruitment. The journal of pain : official journal of the American Pain Society, 19 (2). pp. 178-185. ISSN 1526-5900 doi: https://doi.org/10.1016/j.jpain.2017.09.009 Available at https://centaur.reading.ac.uk/73918/

It is advisable to refer to the publisher's version if you intend to cite from the work. See Guidance on citing.

To link to this article DOI: http://dx.doi.org/10.1016/j.jpain.2017.09.009

Publisher: Elsevier

All outputs in CentAUR are protected by Intellectual Property Rights law, including copyright law. Copyright and IPR is retained by the creators or other copyright holders. Terms and conditions for use of this material are defined in the End User Agreement.

\section{www.reading.ac.uk/centaur}

\section{CentAUR}


Central Archive at the University of Reading

Reading's research outputs online 


\section{Accepted Manuscript}

Title: Sex-Specific Effects of Gender Identification on Pain Study Recruitment

Author: Mattos Feijó L., Tarman G.Z., Fontaine C., Harrison R., Johnstone T., Salomons T.V.

PII:

S1526-5900(17)30738-1

DOI: $\quad$ https://doi.org/doi:10.1016/j.jpain.2017.09.009

Reference: $\quad$ YJPAI 3474

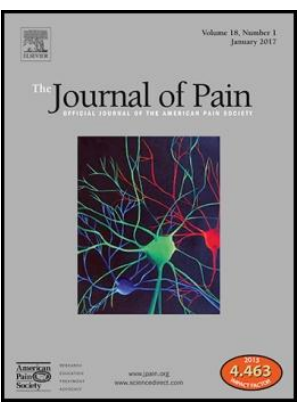

To appear in: The Journal of Pain

Received date: $19-4-2017$

Revised date: $\quad 4-9-2017$

Accepted date: 8-9-2017

Please cite this article as: Mattos Feijó L., Tarman G.Z., Fontaine C., Harrison R., Johnstone T., Salomons T.V., Sex-Specific Effects of Gender Identification on Pain Study Recruitment, The Journal of Pain (2017), https://doi.org/doi:10.1016/j.jpain.2017.09.009.

This is a PDF file of an unedited manuscript that has been accepted for publication. As a service to our customers we are providing this early version of the manuscript. The manuscript will undergo copyediting, typesetting, and review of the resulting proof before it is published in its final form. Please note that during the production process errors may be discovered which could affect the content, and all legal disclaimers that apply to the journal pertain. 


\section{Sex-specific effects of gender identification on pain study recruitment}

Authors: Mattos Feijó, L ${ }^{1,2}$; Tarman, $\mathbf{G Z}^{1}$; Fontaine, $\mathrm{C}^{1}$; Harrison ${ }^{1}, \mathbf{R}^{1}$; Johnstone, $\mathrm{T}^{1}$; Salomons $\mathrm{TV}^{1}$

1 - School of Psychology and Clinical Language Sciences, University of Reading, Reading UK

${ }^{2}$ - Biomedical Sciences Institute, Federal University of Rio de Janeiro

Number of pages: 21

Number of figures: 2

Number of tables: 3

Corresponding author:

Dr. Tim Salomons

University of Reading, Earley Gate

P.O. Box 238, Reading UK, RG6 7BE

E-mail: t.v.salomons@reading.ac.uk

Phone: $+44(0) 1183788524$

Fax: $+44(0) 1183786715$

Personal institutional page: https://www.reading.ac.uk/Psychology/About/staff/t-v-

salomons.aspx

\section{Disclosures:}

LMF was funded by the Brazilian National Council for Scientific and Technological Development (CNPq). RH was funded by a Health Sciences Studentship jointly funded by the University of Reading and the Royal Berkshire Hospital. TVS was funded by a Marie Curie International Incoming Fellowship from the European Commission. The authors have no conflicts to disclose. 


\section{Highlights}

*We measured gender in males and females, then asked them to participate in a pain study

*Males who agreed to participate were higher in masculine gender identification

${ }^{*}$ Aggressive and competitive males were most likely to participate

Abstract: Epidemiological, clinical and laboratory studies show sex

differences in pain responses, with women more sensitive to nociceptive stimulation and more vulnerable to long term pain conditions than men. Given evidence that males are culturally reinforced for the ability to endure (or underreport) pain, some of these findings might be explained by socio-cultural beliefs about gender-appropriate behaviour. One potential manifestation of these effects might be differential participation in pain studies, with males adhering to stereotypical masculine roles viewing participation as a way to demonstrate their masculinity. To test this possibility, we assessed gender identification in 137 healthy participants. At the end of the assessment, they were asked if they would like to participate in other research studies. Interested participants were then asked to participate in a study involving administration of pain-evoking stimulation. We compared individuals who agreed to participate in the pain study to those who declined. We observed a significant sex by participation interaction in masculine gender identification, such that males (but not females) who agreed to participate identified significantly more with masculine gender. Among masculine gender traits examined, we found that high levels of aggression and competitiveness were the strongest predictors of pain study participation. Our results suggest that male samples in pain studies might have higher levels of masculine gender identification than the wider male population. Taken together with previous findings of lower pain sensitivity (or reporting) in 
masculine-identifying males, these results suggest an explanation for some of the sex-related differences observed in pain responses.

Perspective: To examine whether sex and gender affect willingness to participate in pain studies, we assessed gender identification in male and female participants, then attempted to recruit them to participate in a pain study. Males who agree to participate in pain studies are significantly higher in masculine gender identification than males who decline to participate or females who agree to participate. Males who agreed to participate were particularly high in aggressiveness and competitiveness.

Keywords: Sex; Gender; Study Participation; Pain; Masculine Gender Identification 


\section{Introduction}

There is a clinically significant gap between pain levels reported by males and females. Women report pain more frequently [17, 32, 45, 53], across and within more clinical conditions [54] and have a higher risk of developing many common chronic pain conditions $[9,38,71]$. They utilize more health care resources for pain relief [10] and are more likely to consider their healthcare targets unmet after treatment [58]. Experimental studies also report sex differences, although its strength depends on how and when pain is evoked and measured, depending on pain modality [49], assessment tools used, time point of measurement $[17,18,46,47]$ and modulatory processes $[20,55,56]$.

Explanations for observed sex differences often focus on biological mechanisms [4]. An alternative but complementary approach is to examine them at a sociocultural level. Beliefs about gender appropriate behaviour are of particular interest. Men and women believe that men generally have higher pain endurance, lower sensitivity and are less likely to report pain they are experiencing [50]. It suggests social beliefs about masculinity and femininity might influence observed pain responses, as expressing pain is viewed as inconsistent with "masculine" behaviour.

Personal gender identification also seems to influence measurement and experience of pain. A recent meta-analysis found that participants who identify more with masculine roles displayed higher pain threshold and tolerance [2]. Effects appear to be sex-specific: greater masculine gender identification in men, but not women, is associated with increased pain threshold and tolerance in experimental studies [44, 48]. When primed with gender-stereotyped expectations about pain tolerance, women displayed higher pain thresholds and 
lower pain ratings - comparable to their male counterparts - as opposed to a no-priming situation [51]. Men, but not women, show increased pain thresholds when tested by a female experimenter, compared to those tested by male experimenters [21], especially if the female experimenter is dressed in a way that accentuates stereotypical feminine characteristics, which could result in males reverting to gender-typical roles [34]. Male subjects show decreased pain intensity when observed by a female audience [68]. When primed with a feminine gender role (by recalling and writing down instances in which they behaved stereotypically feminine), men displayed less sensitivity to pain relative to women [19].

These findings indicate that adhering to traditional gender roles and experiencing a context that elicits exaggerated behaviours associated with those roles may alter pain reports, especially in men. Given the potential for this cultural reinforcement of pain endurance in males, a potential source of sex effects observed in pain studies could be that males adhering to stereotypical masculine roles will be more likely to enter pain studies, in order to assert their masculinity. This would suggest that selective sampling could inflate observations of sex differences in pain studies. To investigate this, we examined whether biological sex and gender identification influence an individual's willingness to participate in a pain study. Our hypothesis was that males who agree to participate in pain studies identify more with masculine stereotypical gender roles than females or males who refuse to participate. 


\section{Methods:}

Participants:

A total of 137 volunteers (77 women; mean age 24.6 , range $18-47$, $S D=5.5)$ participated in the study. Participants were recruited from the student population at the University of Reading by responding to advertisements placed around the campus and messages posted on university web pages. The text of these ads was as follows: "Looking for healthy volunteers (aged 18-55) to fill out a series of questionnaires examining personality traits and emotional style. Participants will receive financial compensation and will be entered into a pool for participation in other paid studies". Individuals unable to complete questionnaires in English were excluded. As it was critical that participants not discern the study rationale (evaluating willingness to participate in pain studies) students from the Principal Investigator's (TVS) home Department (Psychology) were also excluded. The study was approved by the University Research Ethics Committee at the University of Reading and all participants provided informed consent.

\section{Design Overview:}

The study was completed in a single one-hour session which participants completed alone at a computer terminal. It was divided in three stages, as shown in Figure 1. The first stage obtained information about participants' biological sex and gender identification. Gender identification was measured using the BEM Sex Role Inventory (BSRI) [5], a 60-item self-report measuring masculine and feminine gender identification. In the BSRI, participants rate how descriptive a certain item is of themselves on seven-point Likert scale ranging from 1 (never or almost never true) to 7 (always or almost always true). Twenty 
items indicate stereotypical feminine characteristics (e.g., affectionate, tender, gentle), twenty are stereotypical masculine traits (e.g., dominant, assertive, competitive) and the last twenty considered as neutral items (e.g., truthful, friendly, helpful). Results are given as masculinity and femininity scores respectively the sum of ratings for all masculine and feminine items, varying from 7 to 140. Participants also completed additional questionnaires, which were not included in the present analysis (see below).

The last two stages intended to divide participants according to their willingness to participate in a pain study. To screen out individuals who simply didn't want to participate in further research of any kind, the second stage asked whether participants were interested in participating in future studies for which they might be eligible. They were told these studies were being run by other investigators and weren't connected to the current study. Individuals who agreed to participate in research moved on to the third and final stage, where they were given three study options to choose from for future participation, only one of which was currently recruiting. Options were provided to mask connection with the current study (so that participants didn't feel obligation to the experimenter) and to ensure that participants didn't think the pain study was their only opportunity for financial gain. Participants were told the "currently recruiting" study involved painful stimulation and that whether or not they chose to participate, they would still be eligible for the other studies once they began recruiting. Description of the pain study indicated that the research would investigate the relationship between sensory stimuli and pain perception and that it would involve the administration of painful levels of heat. Participants who refused to take part in the pain study were asked to give their reason, allowing 
us to affirm that participants were declining due to unwillingness to participate in a study involving pain.

At the end of the third stage, our study divided participants into Decliners and Participators. Decliners consisted of participants who agreed to take part in another study but refused to take part after it was revealed the study would involve pain. Participators, on the other hand, consisted of participants who agreed to participate in a pain study. Participants who refused to participate in any other study at stage two were not included in the analysis.

Statistical Analyses:

In order to identify whether gender identification differed between Decliners and Participators and as a function of biological sex, we conducted separate 2-Way Analyses of Variance (ANOVA) for masculine and feminine gender identification, with sex (male and female) and participation (Decliners and Participators) as independent variables. We conducted simple effects tests to examine whether masculine and feminine traits differed between males and females willing or declining to participate in pain research. By doing so, we were able to identify if males who agree to participate in pain studies identify more with stereotypical gender roles than females or males endorsing fewer masculine characteristics. Partial eta squared was calculated as an indicator of effect sizes for significant results.

To elucidate the core masculine traits associated with participation in pain studies, we ran a backwards likelihood ratio logistical regression model to identify the most predictive variables. As an initial step we ran correlations between masculine traits and participation rates. Significant variables 
(aggressive, athletic, competitive, dominant, self-reliant and self-sufficient) were entered into the model.

Analyses were performed using the Statistical Program for Social Sciences (SPSS) version 21.0.

\section{Questionnaires:}

At the first stage, participants filled psychological questionnaires on a computer. In addition to the BSRI, a number of measures were collected on an exploratory basis for an earlier student project analysis $(n=67)$. This included the Big Five Inventory [26], Difficulties in Emotion Regulation Scale [22], Behavioural Inhibition/Behavioural Activation [12], Pain Catastrophizing Scale [61], Domain-specific Risk-attitude Scale [70] and Inventory of Statements About Self-Injury [30, 31]. Only gender was significantly associated with participation in that initial sample (see below). A subsequent student project aimed to increase the reliability and generalizability of this initial finding by increasing the proportion of males in the sample. To maintain a consistent experience for participants, all measures were collected in the second sample ( $n=70 ; 36$ males) but no analysis was conducted on them.

\section{Results:}

The percentage of individuals declining at each stage is provided in Table 1, broken down by Sex. Nine individuals provided reasons for unwillingness to participate in any research. Most of these reflected scheduling (e.g. "Lack of time", "Busy schedule"). Males and females did not differ in their willingness to take part in non-pain related research $(F=1.79, p=0.18)$. The most frequent reason provided for unwillingness to participate in pain research was pain (9/15 males, 12/25 females, example response "I do not want to feel pain, 
even for money"). Some (1/15 males, 3/25 females) cited health/safety concerns (e.g. "Being harmed from the test"). Given that the only information provided about the study at this stage was that it involved administration of painful stimuli, health/safety concerns likely reflected unwillingness to experience pain. Males and females didn't differ in percentage citing pain vs. health/safety $\left(x^{2}=0.45, p=0.5\right)$. Remaining individuals gave no reason or provided non-descript responses (e.g. "I just don't want to").

As expected, males endorsed significantly higher levels of masculine identification $(M / S D=97.6 / 15.1)$ than females $(M / S D=90.4 .6$; $S D=14.9)(F=7.6$; $p<0.05)$. Similarly, females endorsed significantly higher levels of feminine identification $(M / S D=97.5 / 14.3)$ than males $(M / S D=89.3 / 13.7)(F=11.5, p<0.01)$. Males and females did not differ in age $(M / S D=24.7 / 5.5$ for males, 24.5/5.5 for females; $F=0.06, p=0.81$ ).

To determine whether participation status was associated with gender identification and whether it differed as a function of sex, we tested the sex by participation interaction for masculine and feminine gender identification separately. This interaction was significant for masculinity $(F=7.5 ; p<0.01$, $\eta^{2}=0.06$ ), indicating a sex-specific relationship between willingness to participate in pain studies and masculine gender identification. The corresponding interaction was not significant for feminine gender identification $(F=1.3, p=0.26)$, nor were any significant associations between feminine gender identification and willingness to participate observed in either males or females. These interaction effects were not altered when age was included as a covariate. There was no significant sex by participation by sample interaction $(F=0.2, p=0.17)$ for masculine identification, or participation by sample 
interaction for the same variable within males $(F=1.3, p=0.26)$ indicating that the two samples did not differ in terms of the effects of interest. There was no sex by participation interaction for participation in non-pain studies, either for masculine $(F=0.27, p=0.6)$ or feminine $(F=0.27, p=0.9)$ traits.

To further investigate the significant sex by participation interaction for masculine gender identification, simple effects were calculated for participation for each sex. Males in the Participators group endorsed significantly higher levels of masculinity $(M / S D=101.1 / 13.3)$ than their counterparts in the Decliners group $(M / S D=89.7 / 14.8)\left(F=7.1, p=0.01, \quad \eta^{2}=0.06\right)$;. A similar relationship between participation and masculine gender identification was not observed in females $(M / S D=88.5 / 13.9$ for Participators; $M / S D=92.3 / 14.5$ for Decliners $)(F=1.2, p=0.28)$. Results are displayed in Figure 2.

Additional simple effects tests compared males and females in Participators and Decliners groups. In Participators, males and females differed on masculine identification; male participators endorsed significant higher levels of masculinity $(M / S D=101.1 / 13.3)$ than female Participators $(M / S D=88.5 / 13.9)\left(F=15.1, \quad p<0.01, \eta^{2}=0.12\right)$. Males who declined to participate $(M / S D=89.7 / 14.8)$ were not significantly different from females $(M / S D=92.3 / 14.5)$ in terms of masculine identification $(F=0.3, p=0.56)$. Together, these findings indicate that males who agree to participate in pain studies endorse significantly higher masculine traits than either women who agree to participate or non-participating men. Men and women did not differ in willingness to participate overall $(F=0.2, p=0.6)$.

Results of the logistic regression are displayed in Table 2. A significant and parsimonious predictive model $\left(X^{2}(2)=14.3, p=.001\right)$ was obtained after 5 
steps, displaying prediction success overall of $75.0 \%$ (43.8\% for Decliners and 90.6\% for Participators) with a Cox and Snell $R^{2}$ of 0.26 . This model consisted of two variables, both of which were significant within the model: aggression $(\beta=-0.77, p=.02)$ and competitiveness $(\beta=-0.46, p=.03)$, indicating that the more aggressive and competitive a man, the more likely he is to agree to participate in pain studies. Individually, each trait was significantly higher in Participators than Decliners (M/SD for competitiveness $=5.6 / 1.7$ for Participators, $4.1 / 1.8$ for Decliners, $F=6.9, p<0.01$; for aggressiveness $=3.5 / 1.4$ for Participators, $2.3 / 1.2$ for Decliners, $F=7.9, p<0.01)$. Scores for aggressiveness and competitiveness (as well as masculine and feminine traits) by Sex are provided in Table 3.

\section{Discussion:}

The main objective of this study was to explore whether males who agree to participate in pain studies identify more with stereotypical gender roles than females or males endorsing fewer masculine characteristics. Our results show that males who agree to participate in pain research endorse significantly more stereotypical masculine traits than those who decline to participate. Importantly, this is a sex-specific effect: no such difference was found for women, whose willingness to participate was unrelated to gender identification. These findings provide an important context for recent research showing that experimentally induced pain reports are influenced by social beliefs about gender roles [4, 46, 47]. Taken together with this previous work, our results suggest that one factor influencing observed sex differences in pain responses might be that pain studies selectively recruit males for whom underreporting pain could reinforce valued gender identity. 
Social theories of learning and development propose that the identification with a specific gender and learning of congruent gender behaviours develop during childhood and are continually shaped by experience gained in both unique (e.g. family, peers) and shared (e.g. media, school) social contexts $[6,8,11,28,37,42,63]$. In the context of pain, males are expected to withstand (or underreport) pain, displaying toughness rather than responses associated with feminine gender roles [34].

The process of socialization towards sex-typed behaviour begins in childhood and increases during puberty, when physical changes reinforce these pressures $[39,52]$. Young girls are significantly more likely than boys to express feeling pain and sadness [73]. They also report feeling free to discuss their pain with peers whereas boys feel reluctant to express their pain to others [23]. Among boys, exhibitions of emotional distress or pain often result in peer's negative responses and are avoided [43]. Their transgressions are also seen as more negative compared to females', especially by male peers $[8,35]$. They are also punished more harshly and frequently by their parents for incongruent behaviours $[15,33,36]$. In experimental settings boys, but not girls, who score higher on masculinity display lower self-report ratings of heat pain intensity and unpleasantness of pain than boys or girls who identified more strongly with feminine stereotypic roles [40]. Even as adults, men feel embarrassed with having to disclose their pain to others and, therefore, are less prone to do it - as opposed to women, who show a high likelihood of disclosing it [29]. While these findings are consistent with developmental socialization toward muted pain expression in males, we note that much of the literature upon which this interpretation is founded reflect study of a different generation that the 
participants in this study. There is a need for these developmental models to be updated, due to the sociological alterations in gender roles over the past two decades [28].

Examining sex differences in pain reporting at the level of sociocultural beliefs provides an alternate approach to an issue that has traditionally been examined at the level of biology $[1,14,21,34,48,51,62]$. This has a number of implications for future research. First, it might provide an explanation for the fact that while sex differences in pain are routinely observed in clinical and experimental settings, some studies report no sex differences [17, 41, 46, 47, $64,67]$. In such cases, the divergent results may reflect the need to control for gender-homogenous samples. It also provides a practical way to quantify and control for the degree to which observed sex differences in pain responsivity (and/or reporting) are attributable to selective sampling of males identifying with perceived masculine gender roles. Further research is also needed to understand how these sociocultural beliefs reflect or interact with biological factors.

To further characterize these differences, we identified specific masculine traits associated with willingness to participate in a pain study. Willingness to participate had a particularly strong relationship with aggression and competitiveness. A possible interpretation is that individuals with these traits view enduring pain in the context of a pain study as an opportunity to assert masculine behaviour. Vandello and colleagues have suggested that when a man faces actual or perceived societal challenges to masculine status ("precarious manhood") he may attempt to reassert his status by publicly displaying stereotypical masculine behaviors $[65,66]$. These typically take the 
form of aggressive or competitive behaviours [24, 59, 60, 66, 69]. Males high in aggressive and competitive traits might therefore be particularly drawn to opportunities to test and reassert their masculine identity. Since pain expression is viewed as demasculinising by men [27] and the endurance of pain is portrayed as part of the achievement of manhood [57, 72] stoic endurance of pain might be one such opportunity. Consistent with this idea men showed significantly higher pain tolerance as well as aggressive-related emotion activation (on completion of ambiguous word stems in aggressive terms) than their non-threatened counterparts when confronted with gender-threatening cues [7].

Clearly characterizing samples within pain studies is critical. Examining sex and gender characteristics is particularly important, given observed sex differences in pain-related behavior. The findings of this study suggest that over-sampling of men identifying with typical male gender roles might be a critical factor in better understanding sex differences observed in pain studies. Better understanding of these issues will require addressing some limitations of the present study. First, though the BSRI continues to be widely used, it may not reflect the sociological transformation of gender roles since its inception in the mid-70s $[3,13,25,28]$. In particular, some authors have suggested a shift away from dichotomous male/female gender role characterization $[3,16]$. Thus, further study might be accompanied by examination of the continued construct validity of this measure, or use of an alternate measure such as the Gender Role Expectations of Pain measure [74]. Relatedly, changes in attitudes about gender identity may lead to age-related differences in how such attitudes affect 
pain studies. Given that the present study sampled college-age individuals, it is therefore critical to also study different age groups.

A second issue that needs to be addressed in future studies is whether initial indication of willingness to participate reflects actual study participation. The current study did not bring subjects in for an actual pain study. We can therefore not rule out that these findings reflect sex and gender differences in the expression of willingness or intention to participate, rather than actual participation rates. We note, however, that males and females did not differ in willingness to participate in non-pain research, nor were there sex by participation interactions with respect to gender, indicating that it is unlikely that observed effects were due to motivations to take part in research studies in general (e.g. financial gain), and were in fact specific to pain studies. Nevertheless, conducting a similar study in advance of an actual pain experiment and analyzing differential rates of actual participation (compared with initial willingness and with participation in non-pain experiments) would help to clarify these effects.

It should also be noted that these findings emerged from an exploratory approach to characterizing samples in pain studies. Our initial examination cast a wide net, examining risk-taking and self-harm behaviors, affective style and personality variables. None of these were significantly associated with participation in our initial sample and they were therefore not analyzed in the larger sample. Nevertheless, initial inclusion of these measures does increase the possibility of incidental findings. Although no significant difference was observed between samples in the effects of interest, replication of these results would increase confidence. 
In summary, gender identification impacts willingness to participate in pain studies. This effect is specific to males such that the more masculine a man considers himself to be, the more likely he is to agree to enter a pain study. Among the masculine traits examined, aggression and competitiveness were particularly strong predictors of willingness to participate in pain studies in men. Our results suggest that male samples in pain studies might not fully represent the wider male population. These findings place limitations on the generalizability of pain studies and offer a tractable explanation for some of the sex-related differences observed in pain responses in these studies. 


\section{References:}

[1] Alabas OA, Tashani OA, Johnson MI. Gender role expectations of pain mediate sex differences in cold pain responses in healthy Libyans. Eur J Pain; 16:300-11, 2012.

[2] Alabas OA, Tashani OA, Tabasam G, Johnson MI. Gender role affects experimental pain responses: a systematic review with meta-analysis. Eur J Pain; 16:1211-23, 2012.

[3] Auster CJ, Ohm SC. Masculinity and femininity in contemporary American society: A reevaluation using the Bem Sex-Role Inventory. Sex Roles; 43:499528, 2000.

[4] Bartley EJ, Fillingim RB. Sex differences in pain: a brief review of clinical and experimental findings. Br J Anaesth; 111:52-8, 2013.

[5] Bem SL. On the utility of alternative procedures for assessing psychological androgyny. J Consult Clin Psychol; 45:196,1977.

[6] Bernardes SF, Keogh E, Lima ML. Bridging the gap between pain and gender research: a selective literature review. Eur J Pain; 12:427-40, 2008.

[7] Berke DS, Reidy DE, Miller JD, Zeichner A. Take it like a man: Genderthreatened men's experience of gender role discrepancy, emotion activation, and pain tolerance. Psychol Men Masc; 18:62, 2017.

[8] Blakemore JE. Children's beliefs about violating gender norms: Boys shouldn't look like girls, and girls shouldn't act like boys. Sex Roles; 48:411-9, 2003.

[9] Bouhassira D, Lantéri-Minet M, Attal N, Laurent B, Touboul C. Prevalence of chronic pain with neuropathic characteristics in the general population. Pain ; 136:380-7, 2008.

[10] Briscoe ME. Why do people go to the doctor? Sex differences in the correlates of GP consultation. Soc Sci Med; 25:507-13, 1987.

[11] Bussey K, Bandura A. Social cognitive theory of gender development and differentiation. Psychol Rev; 106:676, 1999.

[12] Carver CS, White TL. Behavioral inhibition, behavioral activation, and affective responses to impending reward and punishment: The BIS/BAS Scales. J Pers Soc Psychol; 67:319, 1994.

[13] Carver LF, Vafaei A, Guerra R, Freire A, Phillips SP. Gender differences: Examination of the 12-item Bem Sex Role Inventory (BSRI-12) in an older Brazilian population. PloS one; 8:e76356, 2013. 
[14] Dixon KE, Thorn BE, Ward LC. An evaluation of sex differences in psychological and physiological responses to experimentally-induced pain: a path analytic description. Pain; 112:188-96, 2004.

[15] Fagot BI, Hagan R. Observations of parent reactions to sex-stereotyped behaviors: Age and sex effects. Child Dev; 1:617-28, 1991.

[16] Fernández J, Coelleo MT. Do the BSRI and PAQ really measure masculinity and femininity? Span J Psychol; 13:1000-9, 2010.

[17] Fillingim RB, King CD, Ribeiro-Dasilva MC, Rahim-Williams B, Riley JL. Sex, gender, and pain: a review of recent clinical and experimental findings. $J$ Pain; 10:447-85, 2009.

[18] Fillingim RB, Maixner W, Kincaid S, Silva S. Sex differences in temporal summation but not sensory-discriminative processing of thermal pain. Pain; 75:121-7, 1998.

[19] Fowler SL, Rasinski HM, Geers AL, Helfer SG, France CR. Concept priming and pain: an experimental approach to understanding gender roles in sex-related pain differences. J Behav Med; 34:139-47, 2011.

[20] George SZ, Wittmer VT, Fillingim RB, Robinson ME. Sex and pain-related psychological variables are associated with thermal pain sensitivity for patients with chronic low back pain. J Pain; 8:2-10, 2007.

[21] Gijsbers K, Nicholson F. Experimental pain thresholds influenced by sex of experimenter. Percept Mot Skills; 101:803-7, 2005.

[22] Gratz KL, Roemer L. Multidimensional assessment of emotion regulation and dysregulation: Development, factor structure, and initial validation of the difficulties in emotion regulation scale. J Psychopathol Behav Assess; 26:41-54, 2004.

[23] Hatchette JE, McGrath PJ, Murray M, Finley GA. The role of peer communication in the socialization of adolescents' pain experiences: a qualitative investigation. BMC Pediatr; 8:2, 2008

[24] Hartmann D. The sanctity of Sunday football: Why men love sports. Contexts; 2:13-21, 2003.

[25] Hoffman RM, Borders LD. Twenty-five years after the Bem Sex-Role Inventory: A reassessment and new issues regarding classification variability. Meas Eval Couns Dev; 34:39, 2001.

[26] John, OP, Donahue, EM, Kentle, RL. The Big Five Inventory--Versions 4a and 54. Berkeley, CA: University of California, Berkeley, Institute of Personality and Social Research, 1991.

[27] Keogh E. Men, masculinity, and pain. Pain; 156:2408-12, 2015. 
[28] Keogh E. Sex differences in pain across the life course. Handbook of Pain and Palliative Care. New York: Springer;. pp. 347-366, 2013.

[29] Klonoff EA, Landrine H, Brown M. Appraisal and response to pain may be a function of its bodily location. J Psychosom Res; 37:661-70, 1993.

[30] Klonsky ED, Olino TM. Identifying clinically distinct subgroups of selfinjurers among young adults: a latent class analysis. J Consult Clin Psychol; $76: 22,2008$.

[31] Klonsky ED, Glenn CR. Assessing the functions of non-suicidal self-injury: Psychometric properties of the Inventory of Statements About Self-injury (ISAS). J Psychopathol Behav Assess; 31:215-9, 2009.

[32] Lemley KJ, Senefeld J, Hunter SK, Bement MH. Only women report increase in pain threshold following fatiguing contractions of the upper extremity. Eur J Appl Physiol; 116:1379-85, 2016.

[33] Langlois JH, Downs AC. Mothers, fathers, and peers as socialization agents of sex-typed play behaviors in young children. Child Dev; 1:1237-47, 1980.

[34] Levine FM, De Simone LL. The effects of experimenter gender on pain report in male and female subjects. Pain; 44:69-72, 1991.

[35] Levy GD, Taylor MG, Gelman SA. Traditional and evaluative aspects of flexibility in gender roles, social conventions, moral rules, and physical laws. Child Dev; 1:515-31, 1995.

[36] Lytton H, Romney DM. Parents' differential socialization of boys and girls: A meta-analysis. Psychol Bull; 109:267, 1991.

[37] Martin CL, Ruble DN, Szkrybalo J. Cognitive theories of early gender development. Psychol Bull; 128:903, 2002.

[38] Mogil JS. Sex differences in pain and pain inhibition: multiple explanations of a controversial phenomenon. Nat Rev Neurosci; 13:859-66, 2012.

[39] Moon EC, Unruh AM. The effects of sex and gender on child and adolescent pain. Oxford textbook of paediatric pain. Oxford: Oxford University Press;. pp.127-34, 2014.

[40] Myers CD, Tsao JC, Glover DA, Kim SC, Turk N, Zeltzer LK. Sex, gender, and age: contributions to laboratory pain responding in children and adolescents. J Pain; 7:556-64, 2006.

[41] Niesters M, Dahan A, Kest B, Zacny J, Stijnen T, Aarts L, Sarton E. Do sex differences exist in opioid analgesia? A systematic review and meta-analysis of human experimental and clinical studies. Pain; 151:61-8, 2010. 
[42] O'brien M, Peyton V, Mistry R, Hruda L, Jacobs A, Caldera Y, Huston A, Roy C. Gender-role cognition in three-year-old boys and girls. Sex Roles; 42:1007-25, 2000.

[43] Oransky M, Marecek J. "I'm Not Going to Be a Girl" Masculinity and Emotions in Boys' Friendships and Peer Groups. J Adolesc Res; 24:218-41, 2009.

[44] Otto MW, Dougher MJ. Sex differences and personality factors in responsivity to pain. Percept Mot Skills; 61:383-90, 1985.

[45] Picavet HS, Hazes JM. Prevalence of self reported musculoskeletal diseases is high. Ann Rheum Dis; 62:644-50, 2003.

[46] Racine M, Tousignant-Laflamme Y, Kloda LA, Dion D, Dupuis G, Choinière $M$. A systematic literature review of 10years of research on sex/gender and experimental pain perception-Part 1: Are there really differences between women and men?. Pain; 153:602-18, 2012.

[47] Racine M, Tousignant-Laflamme Y, Kloda LA, Dion D, Dupuis G, Choinière $M$. A systematic literature review of 10years of research on sex/gender and pain perception-Part 2: Do biopsychosocial factors alter pain sensitivity differently in women and men?. Pain; 153:619-35, 2012.

[48] Reidy DE, Dimmick K, MacDonald K, Zeichner A. The relationship between pain tolerance and trait aggression: effects of sex and gender role. Aggress Behav; 35:422-9, 2009.

[49] Riley III JL, Robinson ME, Wise EA, Myers CD, Fillingim RB. Sex differences in the perception of noxious experimental stimuli: a meta-analysis. Pain; 74:181-7, 1998.

[50] Robinson ME, Riley JL, Myers CD, Papas RK, Wise EA, Waxenberg LB, Fillingim RB. Gender role expectations of pain: relationship to sex differences in pain. J Pain; 2:251-7, 2001.

[51] Robinson ME, Gagnon CM, Riley JL, Price DD. Altering gender role expectations: effects on pain tolerance, pain threshold, and pain ratings. J Pain; 4:284-8, 2003.

[52] Rose AJ, Rudolph KD. A review of sex differences in peer relationship processes: potential trade-offs for the emotional and behavioral development of girls and boys. Psychol Bull; 132:98, 2006.

[53] Rosseland LA, Stubhaug A. Gender is a confounding factor in pain trials: women report more pain than men after arthroscopic surgery. Pain; 112:248-53, 2004. 
[54] Ruau D, Liu LY, Clark JD, Angst MS, Butte AJ. Sex differences in reported pain across 11,000 patients captured in electronic medical records. J Pain; 13:228-34, 2012.

[55] Sarlani E, Greenspan JD. Gender differences in temporal summation of mechanically evoked pain. Pain; 97:163-9, 2002.

[56] Sarlani E, Garrett PH, Grace EG, Greenspan JD. Temporal summation of pain characterizes women but not men with temporomandibular disorders. J Orofac Pain; 21:309, 2007.

[57] Seidler VJ. Transforming masculinities: Men, cultures, bodies, power, sex and love. London: Routledge,; 2006.

[58] Socías ME, Koehoorn M, Shoveller J. Gender inequalities in access to health care among adults living in British Columbia, Canada. Women's Health Issues; 26:74-9, 2016.

[59] Swain J. The resources and strategies that 10-11-year-old boys use to construct masculinities in the school setting. Br Educ Res J; 30:167-85, 2004.

[60] Swain J. The resources and strategies boys use to establish status in a junior school without competitive sport. Discourse: studies in the cultural politics of education; 23:91-107, 2002.

[61] Sullivan MJ, Bishop SR, Pivik J. The pain catastrophizing scale: development and validation. Psychol Assess; 7:524, 1995.

[62] Thorn BE, Clements KL, Ward LC, Dixon KE, Kersh BC, Boothby JL, Chaplin WF. Personality factors in the explanation of sex differences in pain catastrophizing and response to experimental pain. Clin J Pain; 20:275-82, 2004.

[63] Tobin DD, Menon M, Menon M, Spatta BC, Hodges EV, Perry DG. The intrapsychics of gender: a model of self-socialization. Psychol Rev; 117:601, 2010.

[64] Turk DC, Okifuji A. Does sex make a difference in the prescription of treatments and the adaptation to chronic pain by cancer and non-cancer patients?. Pain; 82:139-48, 1999.

[65] Vandello JA, Bosson JK. Hard won and easily lost: A review and synthesis of theory and research on precarious manhood. Psychol Men Masc; 14:101, 2013.

[66] Vandello JA, Bosson JK, Cohen D, Burnaford RM, Weaver JR. Precarious manhood. J Pers Soc Psychol; 95:1325, 2008.

[67] Vetrhus M, Berhane T, Søreide O, Søndenaa K. Pain persists in many patients five years after removal of the gallbladder: observations from two 
randomized controlled trials of symptomatic, noncomplicated gallstone disease and acute cholecystitis. J Gastrointest Surg; 9:826-31, 2005.

[68] Vigil JM, Coulombe P. Biological sex and social setting affects pain intensity and observational coding of other people's pain behaviors. Pain; 152:2125-30, 2011.

[69] Weaver JR, Vandello JA, Bosson JK, Burnaford RM. The proof is in the punch: Gender differences in perceptions of action and aggression as components of manhood. Sex Roles; 62:241-51, 2010.

[70] Weber EU, Blais AR, Betz NE. A domain-specific risk-attitude scale: Measuring risk perceptions and risk behaviors. J Behav Decis Mak; 15(4):26390, 2002.

[71] Wijnhoven HA, De Vet HC, Picavet HS. Prevalence of musculoskeletal disorders is systematically higher in women than in men. Clin J Pain; 22:717-24, 2006.

[72] Whitehead S. Men and masculinities: Key themes and new directions. Cambridge: Polity,; 2002.

[73] Zeman J, Garber J. Display rules for anger, sadness, and pain: It depends on who is watching. Child Dev; 67:957-73, 1996.

[74] Robinson ME, Riley JL 3rd, Myers CD, Papas RK, Wise EA, Waxenberg LB,Fillingim RB. Gender role expectations of pain: relationship to sex differences in pain. J Pain. 2:251-7, 2001 
Figure 1: Study design and number of participants per group

Figure 2: Sex by participation interaction in masculine identification score. There was a significant interaction $\left(F=7.2 ; p<0.01, \eta^{2}=0.06\right)$ of sex and participation status, such that men who agreed to participate were significantly higher in masculine identification status (Bem Sex Role Inventory). No difference between Participators and Decliners was observed in females.

Table 1: Proportion of participants choosing to participate in future research at each stage, by Sex.

\begin{tabular}{|c|c|c|c|c|c|c|c|c|}
\hline \multirow{2}{*}{} & \multicolumn{4}{|c|}{ Another study } & \multicolumn{3}{c|}{ Pain Study } \\
\cline { 2 - 10 } & \multicolumn{2}{|c|}{ Yes } & \multicolumn{2}{c|}{ No } & \multicolumn{2}{c|}{ Yes } & \multicolumn{2}{c|}{ No } \\
\cline { 2 - 9 } & $\mathrm{N}$ & $\%$ & $\mathrm{~N}$ & $\%$ & $\mathrm{~N}$ & $\%$ & $\mathrm{~N}$ & $\%$ \\
\hline Men & 47 & 79.7 & 12 & 20.3 & 32 & 68.1 & 15 & 38.9 \\
\hline Women & 69 & 88.5 & 9 & 11.5 & 44 & 63.8 & 25 & 36.2 \\
\hline
\end{tabular}

Table 2: Logistic regression model predicting male participation rates from aggressive and competitive traits. Cox and Snell $R 2=0.24$, model $X 2=13.1, p<0.01$

\begin{tabular}{|c|c|c|c|c|c|c|}
\hline & \multirow[t]{2}{*}{ Coefficients } & \multirow{2}{*}{ Standard Error. } & \multirow[t]{2}{*}{ Sig. } & \multirow[t]{2}{*}{ Odds Ratio } & \multicolumn{2}{|c|}{$95 \%$ C.I.for $\operatorname{EXP}(B)$} \\
\hline & & & & & Lower & Upper \\
\hline Aggressive & -0.74 & 0.32 & 0.02 & 0.48 & 0.26 & 0.89 \\
\hline Competitive & -0.44 & 0.21 & 0.04 & 0.65 & 0.43 & 0.97 \\
\hline Constant & 3.53 & 1.48 & 0.02 & 34.20 & - & - \\
\hline
\end{tabular}

Table 3: Male and female scores on BSRI subscales and on traits associated with participation in logistic regression

\begin{tabular}{|c|r|r|r|r|}
\hline \multirow{2}{*}{} & \multicolumn{2}{|c|}{ Men } & \multicolumn{2}{c|}{ Women } \\
\cline { 2 - 5 } & Mean & SD & \multicolumn{1}{c|}{ Mean } & \multicolumn{1}{c|}{ SD } \\
\hline MasculineTraits & 101.1 & 13.3 & 88.5 & 13.9 \\
\hline FeminineTraits & 89.5 & 15.4 & 96.2 & 14.4 \\
\hline Competitiveness & 5.6 & 1.7 & 4.3 & 1.7 \\
\hline
\end{tabular}




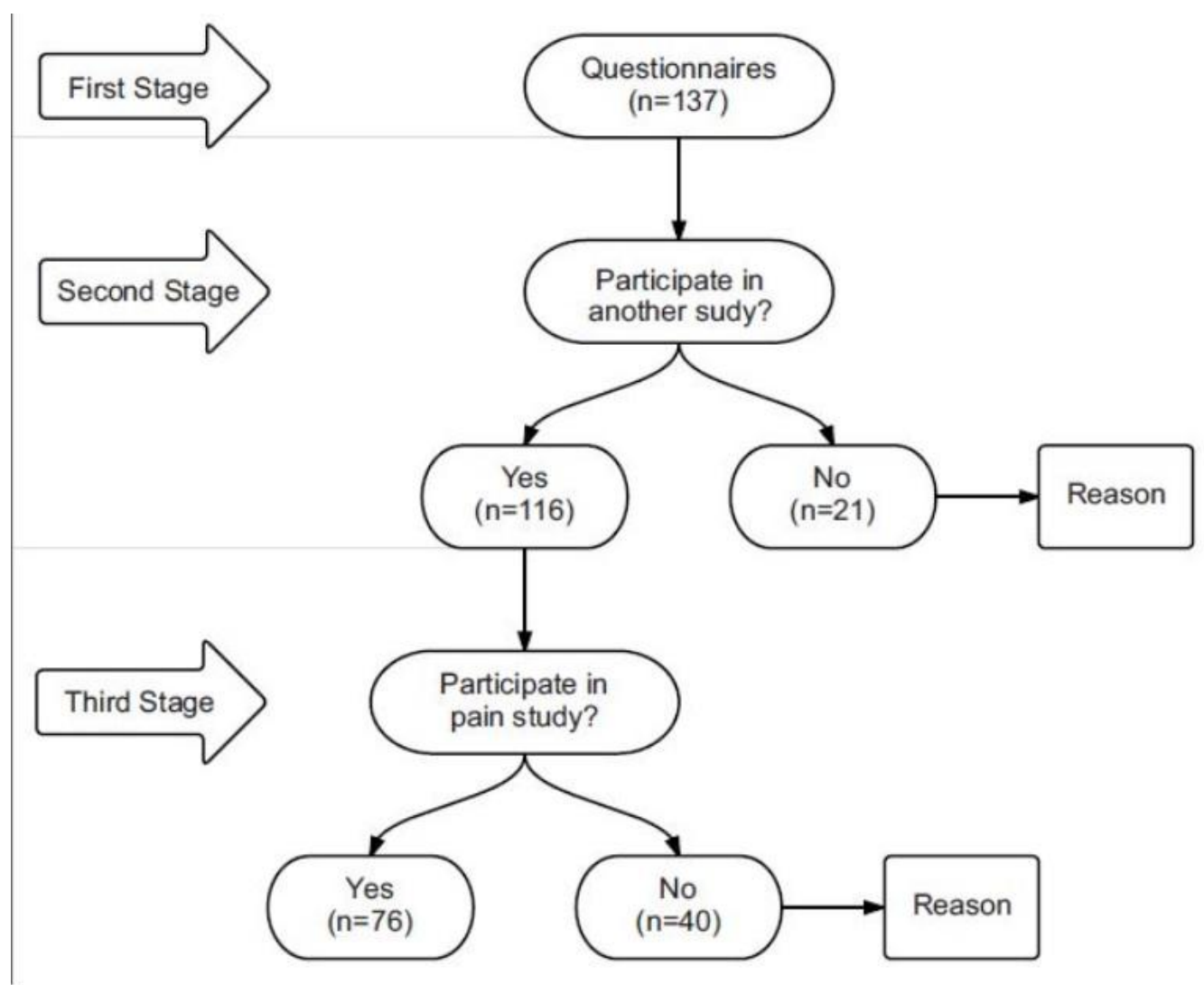

Fig 1 salomons.jpg 


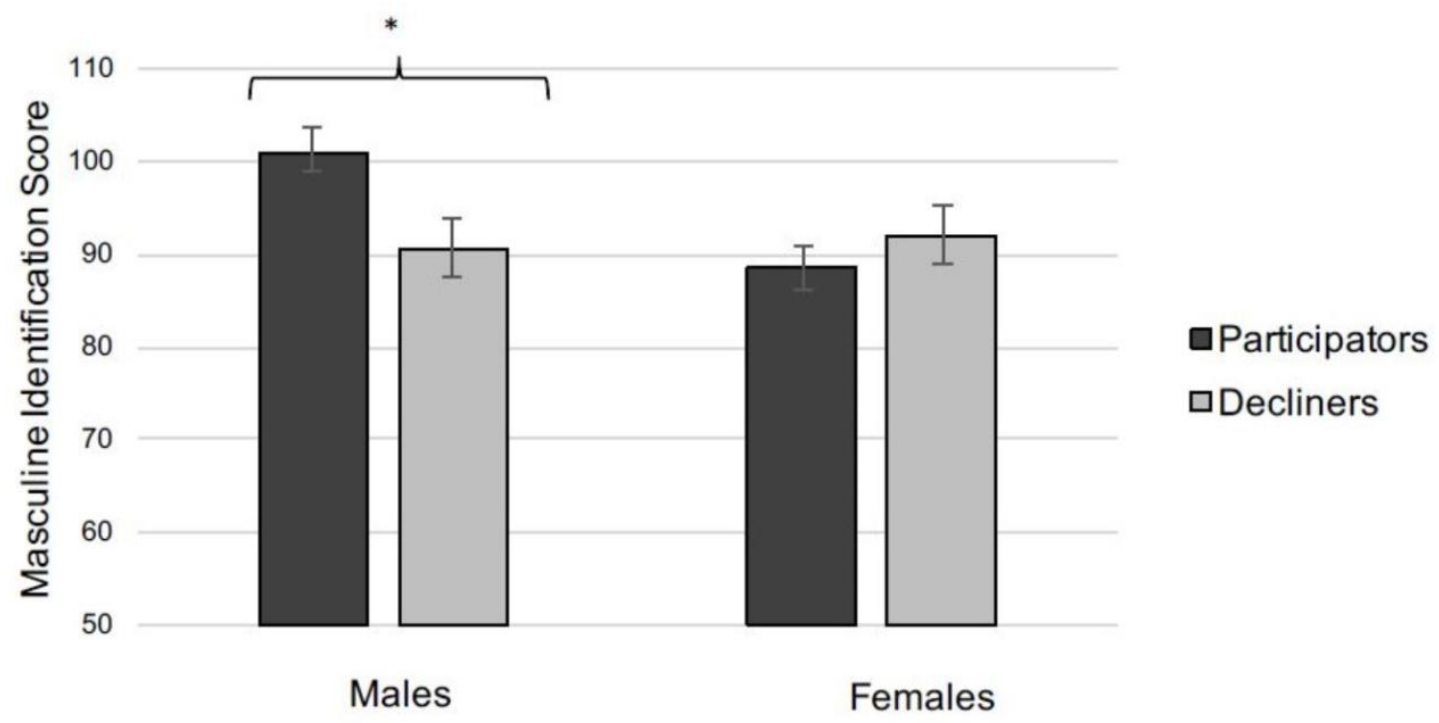

Figure 2 salomons.jpg 